\title{
THE EFFECT OF DIFFERENT PREYS ON BEHAVIOR OF THE PREDATORY MITE AMBLYSEIUS SWIRSKII
}

\author{
Nawar, Mohamed A..$^{*}$ and Iman I. Imam² \\ ${ }^{1}$ Animal Pest Unit, Department of Plant Protection, Desert Research \\ Center, El-Matareya, Cairo, Egypt. \\ ${ }^{2}$ Economic Entomology Unit, Department of Plant Protection, Desert \\ Research Center, El-Matareya, Cairo, Egypt. \\ *E-mail:ma_nawar@yahoo.com
}
T he functional response of the phytoseiid predator Amblyseius swirskii (Acarina:Phytoseiidae) on densities of its prey Tetranychus urticae and Thrips tabaci and Bemisia tabaci, was evaluated under controlled temperature $\left(25 \pm 2^{\circ} \mathrm{C}\right)$, relative humidity $(75 \pm 15 \%)$. Predator exhibited a decelerating curve Type II response determined by a logistic regression model. The linear reciprocal transformation of Holling's disc equation was used to further evaluate the parametric values. Differences in handling times were found to be significant within the prey indicating that predator respond differentially to prey species. Differences in coefficients of attack rates, however, did not vary significantly in most of the treatments. The potential role of this predator in biocontrol of Tetranychus urticae and Thrips tabaci that may be the better predator for the management of both prey species, particularly two-spotted spider mite. However, further field-based studies are needed to confirm this hypothesis.

Keywords: Amblyseius swirskii, Tetranychus urticae, predation, functional response, Thrips tabaci, Bemisia tabaci, Phytoseiidae

The functional response of a predator is a key factor regulating the population dynamics of predator-prey systems. It describes the rate at which a predator kills its prey at different prey densities and can thus determine the efficiency of a predator in regulating prey populations (Murdoch and Oaten, 1975). Functional response is conveniently classified into three general types named I, II and III, which describe, respectively, linear, non-linear with saturation and sigmoid patterns (Holling, 1959 and Hassell, 1978).

The Phytoseiidae are the most common plant inhabiting predatory mites. They have been considered to play an important role in the natural

The $1^{\text {st }}$ Conference of Plant Protection Science Applications for Sustainable Development of Desert Areas "Effect of Climate Change on Plant Pests and Biodiversity in Desert Environment" 19-20 October, 2019, Cairo-Egypt. 
control of some phytophagous mites and insects. Several phytoseiid species have been commercially produced for the control of pest mites, trips and whiteflies (Moraes and McMurtry, 1981). Many species of Phytoseiidae are predators of mite pests; they are thus of huge interest in biological control programs. This family is widespread all over the world and includes three subfamilies and more than 2,000 valid species (Kostiainen and Hoy, 1996 and McMurtry and Croft, 1997). Variation in prey selection behavior, resulting in quantitative and/or qualitative differences in food intake, may results in differences in reproductive success. If this variation is genetically determined, natural selection is expected to favor thus genotypes that maximize their contribution to future generations. It is therefore expected that Phytoseiidae mites do not feed indiscriminately but prefer certain food types over others, (Van Lenteren, 1986).

Amblyseius swirskii Athias-Henriot is a predatory mite endemic to the Eastern Mediterranean region, which is considered as an efficient biological control agent against thrips, whiteflies and phytophagous mites (Swirski et al., 1967; El-Laithy and Fouly, 1992; Gerling et al., 2001; Nomikou et al., 2001, 2003).

The two-spotted spider mite, Tetranychus urticae Koch, is one of the most economically-important greenhouse (Maleknia et al., 2016) and crop pests (Khanamani et al., 2013), with a broad host plant range and an extensive record of pesticide resistance (Leeuwen et al., 2010). An alternative management strategy of this pest is the use of predaceous mites as control agents (Fathipour and Maleknia, 2016).

Biological control of thrips, Thrips tabaci Lindeman with predatory mite releasing began in Egypt on European sweet pepper crops infested with the onion thrips, T. tabaci. Following several years of research, commercial use of predatory mites like Amblyseius cucumeris, A. barkeri (mckenziei) and A. fallacies Garman was begun in 1985 in Holland with releases on about 25\% of the Dutch pepper acreage under glass (De Klerk and Ramakers 1986). Natural enemies, A. fallacies caused reduction of more pests (especially piercing and sucking pests). Predaceous mites play an important role in the biological control of phytophagous mites and some insect pests (Sengonca and Drescher, 2001). A. fallacies feeds on mites on berry and fruit crops, as well as a supplement to Phytoseiulus persimilis in greenhouse situations. A. fallacies can also survive on lower pest densities and feed on a variety of food sources such as two-spotted mites, European red mite and pollen. Predatorprey interactions between Phytoseiids and Tetranychids in Japan revealed that the native predators Amblyseius longispinosus and A. eharai and the introduced predator $P$. persimilis were potential biological control agents of tetranychid mites reported by Mori et al. (1990). Thrips palmi was an important pest of several crops, especially vegetables. The predatory mite $A$. cucumeris was successfully used in the control of various thrips species reported by Cuellar et al. (2002). The predatory mites $P$. persimilis and $A$.

Egyptian J. Desert Res., 69, Special Issue, 47-57 (2019) 
cucumeris in commercial greenhouses for augmentative biological control of thrips used by Opit et al. (2005).

Some predatory mites are effective predators of whitefly Bemisia tabaci MED, such as Amblyseius swirskii (Acari: Phytoseiidae), which has been widely used in Europe and North America (Nomikou et al., 2003 and Calvo et al., 2011). Preliminary studies indicated that $A$. swirskii might have negative impacts on native phytoseiid mite populations if introduced (Yukie and Atsushi, 2011). In addition, biological control is sometimes considered as 'unreliable' because many natural enemies are environmentally sensitive and their performances vary under different conditions (Bale et al., 2008). Therefore, it is always valuable to develop new biological control agents to provide more choices. Currently, limited data about whitefly control capability of native predatory mite species are available in Egypt. The present work aims to study functional response of $A$. swirskii on different pests to clarify predator-prey interaction.

\section{MATERIALS AND METHODS}

\section{Plants, Prey and Predatory Mite}

The bean plants (Phaseolus vulgaris L. var. alamoti) were grown in pots soil in greenhouse. Bemisia tabaci (Gennadius), thrips and T. urticae were originally collected from a greenhouse at Desert Research Center, Cairo, Egypt.

A. swirskii was collected in Egypt on plant infested with B. tabaci and T. urticae. The adults of $A$. swirskii were later transferred onto the detached bean leaves containing ample number of all stages of $T$. urticae as prey in a growth bean at $25 \pm 1^{\circ} \mathrm{C}$. The predator and prey individuals were reared for two generations before using in the experiments.

Bean leaf discs ( $3 \mathrm{~cm}$ diameter) were placed upside down on a wet sponge inside a plastic Petri dish $(6 \mathrm{~cm}$ diameter and $0.5 \mathrm{~cm}$ height $)$. A strip of wet cotton around each leaf disc prevents the mites from scaping. Initial prey densities of $2,4,8,10$, and 12 of different immature pests were replicated 10 times each. During each test, different densities of prey were transferred to the experimental unit by a fine camel's hair brush.

\section{Functional Response Experiment}

The functional response experiments were conducted with $24 \mathrm{~h}$ starved, 3-day old females. Each experiment was carried on with a single starved female per experimental unit without prey replenishment. After $24 \mathrm{~h}$, the females were removed and the predation estimated in terms of number of immature attacked per female. 


\section{Statistical Analysis}

To determine the shape of functional response, a logistic regression of the proportion of prey killed as a function of initial density was used.

$$
N_{e} / N_{0}=\frac{\exp \left(P_{0}+P_{1} N_{0}+P_{2} N_{0}^{2}+P_{3} N_{0}^{3}\right)}{1+\exp \left(P_{0}+P_{1} N_{0}+P_{2} N_{0}^{2}+P_{3} N_{0}^{3}\right)}
$$

$-\mathrm{Ne}$ is the number of prey consumed,

- NO is the initial prey density,

- $(\mathrm{Ne} / \mathrm{NO})$ is the probability of prey consumption,

- $P 0, P 1, P 2$ and $P 3$ are the maximum likelihood estimates of the intercept, linear, quadratic and cubic coefficients, respectively.

These parameters can be estimated by using the CATMOD procedure using SAS program (Juliano, 2001). Negative or positive reactive linear coefficient in the expression fit to data on proportion killed $\mathrm{Ne} / \mathrm{NO}$ versus initial number of prey $N 0$, indicate Type II or Type III functional response, respectively. A non-linear least squares regression of number of prey killed versus initial number of prey was used to estimate and compare parameters of functional responses using the NLIN procedure in SAS. Functional response data were fitted to the random predator equation (Juliano, 2001). This equation considers for prey depletion without replacement of prey during the experiment (Rogers, 1972).

Once the functional response type was determined from logistic regression analyses and log likelihood-ratio tests, iterative non-linear least squares regression (NLIN procedure with Proc method of SAS) (SAS, 2003) was used to estimate the parameters of Holling's disc equation (Eq. 2) (Holling, 1959).

$$
\mathrm{Na}=\mathrm{a} \mathrm{T} \mathrm{N} 0 / 1+\mathrm{a} \text { Th N0 (2) }
$$

Where $\mathrm{T}$ is the time of exposure $(24 \mathrm{~h})$ is the rate of successful attack, and Th, is the handling time. Values of Th, estimated by non-linear least squares regression, were used to calculate maximum attack rate as $\mathrm{T} / \mathrm{Th}$ (Hassell, 2000), that represent the maximal number of preys that could be consumed by a predator of $A$. swirskii during $24 \mathrm{~h}$.

\section{RESULTS AND DISCUSSION}

The logistic regression for predatory mite had a significant linear parameter $P 1<0$ (Table 1) and the proportion of prey consumed by predator declined with increasing prey density (Fig. 1). This suggests the exhibited Type II response. 
An increase in prey density eventually resulted in a higher predation rate. The functional response of $A$. swirskii with immature as prey showed a curvilinear rise to a plateau as seen in table (1) and fig. (1).

The daily feeding of adult $A$. swirskii on immature $T$. urticae, $B$. tabaci and whitefly increased at an accelerated rate when prey density was between 2 and 14 preys.

Predation rate started to level off at a prey density of 2-14. The plateau was reached at approximately 3.38 prey items per day. The average number of immature consumed by one predator per day was $3.38+1.04$, ranging from 0 to 6. Daily predation rate gradually increased when $A$. swirskii was provided at increasing prey densities (Fig. 1). A. swirskii consumed all pray of $T$. urticae, B. tabaci and whitefly in $24 \mathrm{~h}$.

Comparison of the preference indices for A. swirskii when offered equal numbers of T. urticae, B. tabaci and whitefly has been shown in Fig. (1). Although all larval instars of $A$. swirskii showed a good predation potential to $T$. urticae, B. tabaci and whitefly of the predator were more effective in preying on this prey. The higher predation of $A$. swirskii is a logical reflection of its larger size and thus an ensuing higher voracity. The outcome of the logistic regression, that is, the observed versus Ptted probabilities (Table 1 and Fig. 1), indicated that the proportion of prey eaten decreases with increasing prey density, in all bioassays.

Table (1). Results of logistic regression analyses, indicating estimates and standard errors of linear, quadratic and cubic coefficient for the proportion of prey eaten by $A$. swirskii against the initial prey number offered at $25^{\circ} \mathrm{C}$.

\begin{tabular}{cccccc}
\hline $\begin{array}{c}\text { Stage of } \\
\text { A. swirskii }\end{array}$ & Coefficient & Estimate & SE & Chi-Square & $\boldsymbol{p}$ \\
\hline \multirow{5}{*}{ T. tabaci } & Intercept $\mathrm{P}_{0}$ & 0.685300 & 0.143800 & 22.72 & $<0.0001$ \\
& Linear $\mathrm{P}_{1}$ & -3.144800 & 0.749000 & 17.63 & $<0.0001$ \\
& Quadratic $\mathrm{P}_{2}$ & 0.038300 & 0.007680 & 1.50 & $<0.0001$ \\
& Cubic $\mathrm{P}_{3}$ & -0.000883 & 0.000655 & 1.82 & 0.1776 \\
\hline \multirow{5}{*}{ t. urticae } & Linear $\mathrm{P}_{1}$ & 1.807400 & 1.215500 & 2.21 & 0.0137 \\
& Intercept $\mathrm{P}_{0}$ & -6.170100 & 2.857400 & 4.66 & 0.0044 \\
& Quadratic $\mathrm{P}_{2}$ & 0.199100 & 0.161900 & 1.52 & 0.0217 \\
& Cubic $\mathrm{P}_{3}$ & -0.007320 & 0.006740 & 1.18 & 0.0276 \\
\hline \multirow{5}{*}{ tabaci } & Intercept $\mathrm{P}_{0}$ & -7.168600 & 2.520200 & 8.09 & 0.044 \\
& Linear $\mathrm{P}_{1}$ & 2.696600 & 1.089600 & 6.13 & 0.0133 \\
& Quadratic $\mathrm{P}_{2}$ & -0.326200 & 0.146300 & 4.97 & 0.0257 \\
& Cubic $\mathrm{P}_{3}$ & 0.012500 & 0.006140 & 4.15 & 0.0416 \\
\hline
\end{tabular}



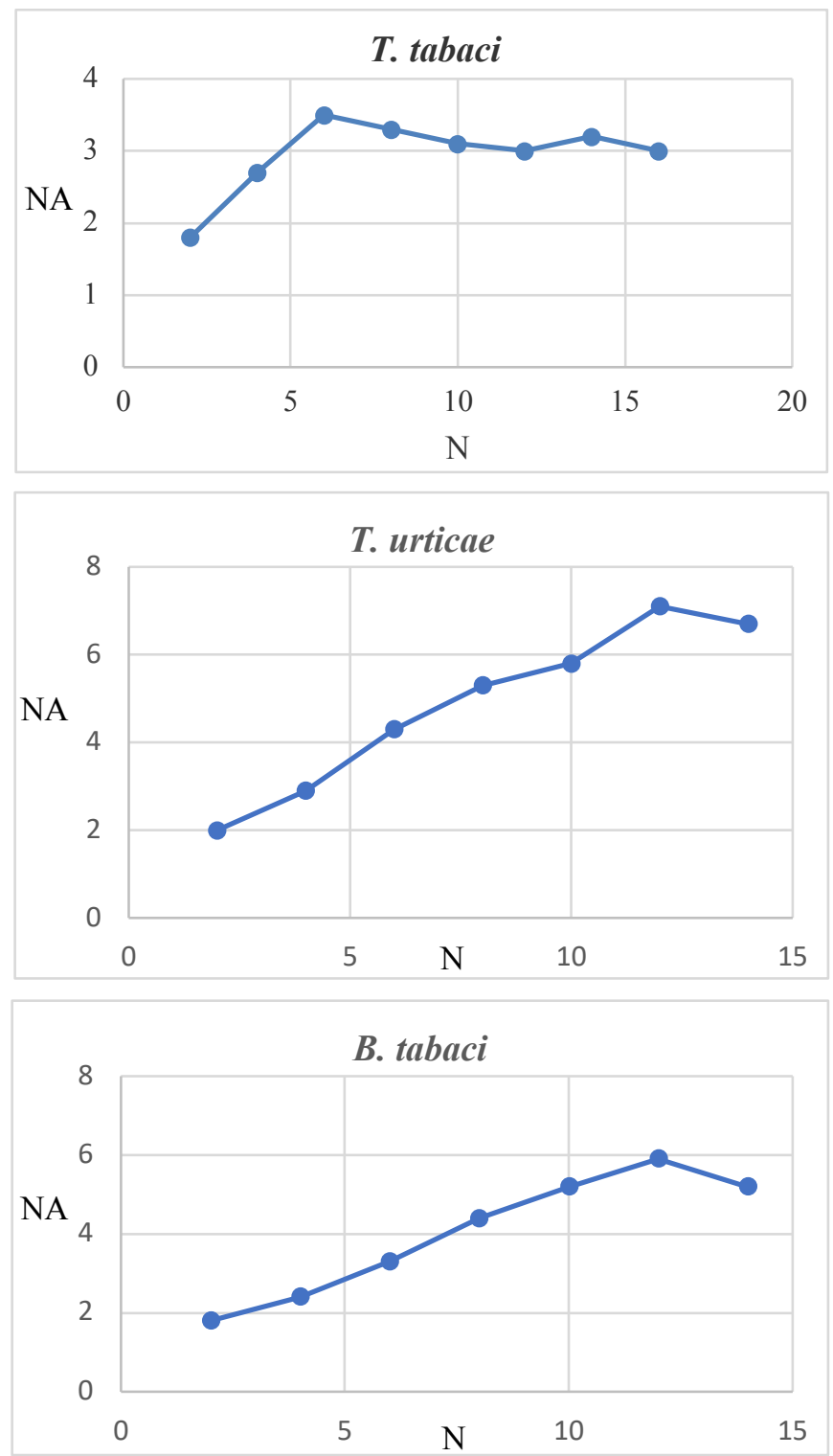

Fig. (1). Functional response and percentage of prey consumed by $A$. swirskii on immature stages of different pests.

The handling times and coefficient of attack rates are presented in table (2), which shows that $A$. swirskii had the handling time using trips, whitefly and $T$. urticae as preys. Both handling time and coefficient of attack rate depended on the prey species with optimal values (Table 2).

Egyptian J. Desert Res., 69, Special Issue, 47-57 (2019) 
Table (2). Effect of different pests on the attack rate (a), handling time $T_{h}$ and the maximum number of consumption $\left(\mathrm{T} / \mathrm{T}_{\mathrm{h}}\right)$ on A. swirskii derived from random predator equation.

\begin{tabular}{ccccccccc}
\hline \multirow{2}{*}{ Stage of } & \multirow{2}{*}{$\mathbf{A}$} & \multicolumn{2}{c}{ Asymptotic 95\% CI } & \multirow{2}{*}{$\mathbf{T}_{\mathbf{h}}$} & & \multicolumn{2}{c}{ Asymptotic 95\% CI } & \multirow{2}{*}{ T/ $\mathbf{T}_{\mathbf{h}}$} \\
\cline { 3 - 4 } & & Lower & Upper & & & Lower & Upper & \\
\hline T. tabaci & $0.0181 \pm 0.00162$ & 0.0149 & 0.02140 & & $0.245 \pm 0.01330$ & -0.051 & 0.00229 & 97.00 \\
T. urticae & $0.0109 \pm 0.0692$ & 0.0330 & 0.00246 & & $0.131 \pm 0.00336$ & -0.824 & 0.54600 & 183.00 \\
B. tabaci & $0.0298 \pm 0.0116$ & 0.0635 & 0.05320 & $0.492 \pm 0.00450$ & -0.014 & 0.04170 & 48.78 \\
\hline
\end{tabular}

\section{DISCUSSION}

It was clearly demonstrated that the increase of prey number was related to the daily consumption number of $A$. swirskii. The predation rate tended to decrease with prey density, probably due to an increasing satiation by predators in patches of higher density. Thus, predation rates followed Type II functional response, which is shared by most phytoseiid predators (Sabelis, 1986).

Aside from the simplicity of the conditions under which these experiments were conducted, the functional response does not by itself show the true regulative power of a predator. Because in spite that the ability of a predator to control depends on the predator's functional and numerical response, this response is influenced by different factors, including behavioral patterns in response to its own densities, developmental response, preference, utilization of alternative prey and intraguild interaction (Lester and Harmsen, 2002).

So, one should take great caution in extrapolating the results of oversimplified laboratory experiments to more complex and heterogeneous field conditions (O’Neil, 1997 and Lester and Harmsen, 2002). O'Neil (1997) considered that high prey density laboratory studies focuses attention on predator consumptive behavior, such as handling time, which are not important when prey attacks are low. Nevertheless, due to their relatively good predatory traits, $A$. swirskii is presumably able to be used in conservation biological control approach against $T$. urticae, B. tabaci and whitefly.

\section{CONCLUSIONS}

The present study has improved our understanding of the A. swirskii - T. urticae - B. tabaci and whitefly interactions, which can be useful for the evaluation to control this pest and thus for development of pest management strategies based on biological control. By including A. swirskii in control programs, the use of pesticides against two-spotted spider mites $T$. urticae, $B$. 
tabaci and whitefly will likely be reduced. However, it is recommended that additional studies are undertaken under more natural conditions to provide further details of these predator-prey interactions.

Although these results obtained in laboratory conditions, this work can help to conclude that predatory $A$. swirskii can be considered as a control agent of $T$. urticae, B. tabaci and whitefly in field and greenhouse conditions.

\section{REFERENCES}

Bale, J.S., J.C. van Lenteren and F. Bigler (2008). Biological control and sustainable food production. Philos. Trans. R. Soc. Lond. B. Biol. Sci., 363: 761-76.

Calvo, F.J., K. Bolckmans and J.E. Belda (2011). Control of Bemisia tabaci and Frankliniella occidentalis in cucumber by Amblyseius swirskii. BioControl, 56: 185-192.

Cuellar, M.E., A.C. Bellotti and E.L. Melo (2002). Aspects of the biology and rate of consumption of Amblyseius cucumeris and Typhlodromus aripa (Acari:Phytoseiidate) on the host Thrips palmi Karny (Thysanoptera:Thripidae). Revista Colombiana de Entomologia, 28 (1): $1-7$.

De Klerk, M.L. and P.M.J. Ramakers (1986). Monitoring population densities of the phytoseiid predator Amblyseius cucumeris and its prey after large scale introductions to control Thrips tabaci on sweet pepper. Mededelingen van de Faculteit Landbouwwetenschappen Rijksuniversiteit Gent, 51 (3a): 1045-1048.

El-Laithy, A.Y.M. and A.H. Fouly (1992). Life table parameters of the two phytoseiid predators Amblyseius scutalis (Athias-Henriot) and $A$. swirskii A.-H. (Acari: Phytoseiidae) in Egypt. Journal of Applied Entomology, 113: 8-12.

Fathipour, Y. and B. Maleknia (2016). Mite predators. In: "Ecofriendly Pest Management for Food Security" (Omkar Ed.). Elsevier, San Diego, USA, p. 329-366.

Gerling, D., O. Alomar and J. Arno (2001). Biological control of Bemisia tabaci using predators and parasitoids. Crop Protection, 20: 779-799.

Hassell, M.P. (1978). In: "The Dynamics of Arthropod Predator-prey Systems". Princeton Univ. Press, Princeton.

Hassell, M. (2000). In "The Spatial and Temporal Dynamics of Host Parasitoid Interactions". Oxford University Press, Oxford, United Kingdom.

Holling, C.S. (1959). The components of predation as revealed by study of small-mammal predation of the European pine sawfly. Can. Entomol., 91: 239-320.

Juliano, S.A. (2001). Nonlinear curve fitting: predation and functional response curves. In: "Design and Analysis of Ecological Experiments

Egyptian J. Desert Res., 69, Special Issue, 47-57 (2019) 
2". (Scheiner, S.M. and J. Gurevitch Eds.). Oxford University Press, New York, p. 178-196.

Khanamani, M., Y. Fathipour and H. Hajiqanbar (2013). Population growth response of Tetranychus urticae to eggplant quality: application of female age-specific and age-stage, two-sex life tables. International Journal of Acarology, 39: 638-648.

Kostiainen, T.S. and M.A. Hoy (1996). In "The Phytoseiidae as Biological Control Agents of Pest Mites and Insects". A bibliography. Monograph 17, University of Florida, Agricultural Experiment Station, $355 \mathrm{pp}$.

Leeuwen, T.V., J. Vontas, A. Tsagkarakou, W. Dermauw and L. Tirry (2010). Acaricide resistance mechanisms in the two-spotted spider mite Tetranychus urticae and other important Acari: A review. Insect Biochemistry and Molecular Biology, 40: 563-572.

Lester, P. and R. Harmsen (2002). Functional and numerical responses not always indicate the most effective predator for biological control: an analysis of two predators in a two-prey system. Journal of Applied Ecology, 39: 455-468.

Maleknia, B., Y. Fathipour and M. Soufbaf (2016). How greenhouse cucumber cultivars affect population growth and two-sex life table parameters of Tetranychus urticae (Acari: Tetranychidae). International Journal of Acarology, 42 (2): 70-78.

McMurtry, J.A. and B.A. Croft (1997). Life-styles of Phytoseiidae mites and their roles in biological control. Annual Review of Entomology, 42: 291-321.

Moraes, G.J. and J.A. McMurtry (1981). Biology of Amblyseius citrifolius (Acarina: Phytoseiidae). Hilgardia, 49: 1-29.

Mori, H., Y. Saito and H. Nakao (1990). Use of predatory mites for controlling spider mites (Acarina: Tetranychidae) in Japan. FFTC-NARC International Seminar on 'The Use of Parasitoids and Predators to Control Agricultural Pests'. Tukuba Science City, Ibarakiken, 305 Japan, 22 pp.

Murdoch, W.W. and A. Oaten (1975). Predation and population stability. Adv. Eco. Res., 9: 1-131.

Nomikou, M., A. Janssen, R. Schraag and M.W. Sabelis (2001). Phytoseiid predators as potential biological control agents for Bemisia tabaci. Exp. Appl. Acarol., 25: 271-291.

Nomikou, M., A. Janssen and M.W. Sabelis (2003). Phytoseiid predators of whiteflies feed and reproduce on non prey food sources. Experimental and Applied Acarology, 31: 15-26.

O'Neil, R. (1997). Functional response and search strategy of Podissus maculiventris (Heteroptera: Pentatomidae) attacking colorado potato beetle (Coleoptera: Chrysomelidae). Environmental Entomology, 26: 1183-1190. 
Opit, G.P., J.R. Nechols, D.C. Margolies and K.A. Williams (2005). Survival, horizontal distribution and economics of releasing predatory mites (Acari: Phytoseiidate) using mechanical blowers. Biological Control, 33 (3): 344-351.

Rogers, D. (1972). Random search and insect population models. Journal of Animal Ecology, 47: 805-816.

Sabelis, M. (1986). The functional response of predatory mites to the density of two spider mites, In: "Dynamics of Physiologically Structured Populations, Lecture Notes in Biomathemathics" (Metz, J. and O. Diekmann Eds.). Springer Verlag, Belin, Germany, p. 298- 321.

SAS (2003). SAS Procedures Guide, Version 9, Release 9.1. SAS Institute Inc., Carey, NC.

Sengonca, C. and K. Drescher (2001). Laboratory studies on the suitability of Thrips tabaci Lindeman (Thsanoptera: Thripidae) as prey for the development, longevity, reproduction and predation of four predatory mite species of the genus Amblyseius (Acari: Phtoseiidae). Zeitschrift fur Pflanzenkrankheiten und Phanzenschutz, 108 (1): 66-76.

Swirski, E., S. Amitai and N. Dorzia (1967). Laboratory studies on the feeding, development and oviposition of the predacious mite Amblyseius rubini Swirski and Amitai and Amblyseius swirski AthiasHenriot (Acari: Phytoseiidae) on various kinds of food substances. Journal of Agricultural Research, 17: 101-119.

Van Lenteren, J.C. (1986). Evaluation, mass production, quality control and release of entomophagous insects. In: "Biological Plant and Health Protection" (Franz, J.M. Ed.). Gustav Fischer, Stuttgart, p. 31-56.

Yukie, S. and M. Atsushi (2011). Risk assessment of non-target effects caused by releasing two exotic phytoseiid mites in Japan: can an indigenous phytoseiid mite become IG prey. Exp. Appl. Acarol., 54: 319-329.

Egyptian J. Desert Res., 69, Special Issue, 47-57 (2019) 


\section{Amblyseius تأثير الفرائس المختلفة على سلوك المفترس الأكاروسي swirskii}

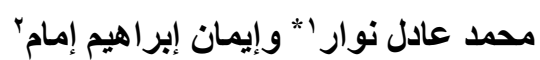

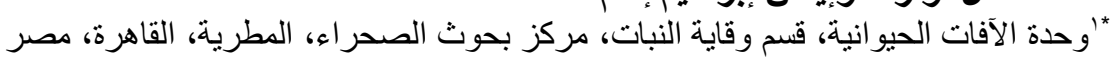

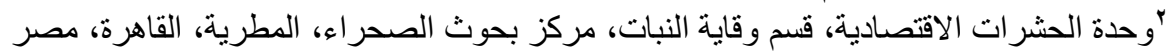

Amblyseius swirskii (Acarina:تم تقييم الإستجابة الوظيفية للمفترس الأكاروسي

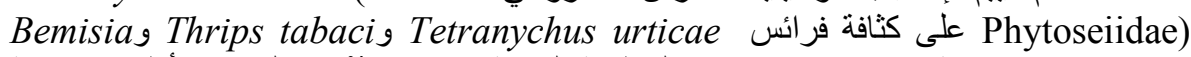
tabaci

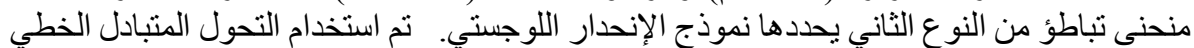

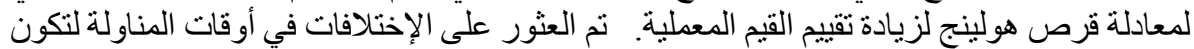

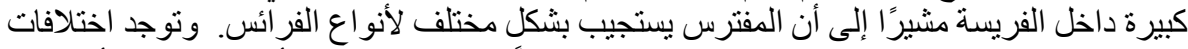

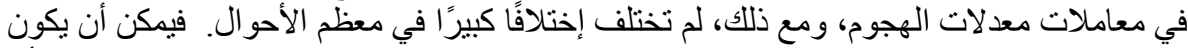

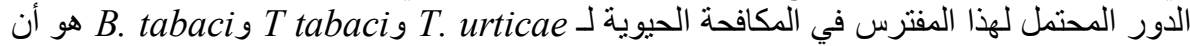
يكون المفترس الأفضل لإدارة الثناثة فر ائس. ومع ذللك، هناك حاجة إلى مزيد من الدراسات الثات الميدانية

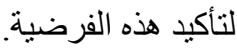

